\title{
Papiller adenofibroma of the cervix: a case report
}

\author{
Abdullah Karaer • Cigdem Demirel • Nedim Gunes • \\ Songul Kose
}

Received: 1 September 2007 / Accepted: 22 January 2008 / Published online: 20 February 2008

(C) Springer-Verlag 2008

\begin{abstract}
Uterine adenofibroma is a rare benign neoplasm that is classified into the mixed epithelial and mesenchymal tumor group. It typically affects the endometrium; involvement of the cervix is an unusual condition. We present a 55year-old woman with the complaint of perimenopausal genital bleeding. Her gynecologic examination revealed a firm, pedunculated $2 \times 2 \mathrm{~cm}$ polypoid lesion on the cervix. A diagnostic polypectomy was performed and histopathological findings of the cervical biopsy specimen confirmed the diagnosis cervical adenofibroma. Although this lesion appears to be histological benign, multiple recurrences, local invasion, and involvement by adenocarcinoma have been reported. Therefore, total hysterectomy with bilateral salpingoophorectomy was performed.
\end{abstract}

Keywords Adenofibroma $\cdot$ Adenosarcoma $\cdot$ Cervical tumor $\cdot$ Mixed mesodermal tumor

A. Karaer $(\triangle) \cdot$ C. Demirel $\cdot$ S. Kose

Department of Obstetrics and Gynecology,

Siirt Women's \& Children's Hospital,

Evren mah. A.Rahman Kavak cad. (Eruh yolu),

56100 Merkez/Siirt, Turkey

e-mail: drkaraer@yahoo.com

N. Gunes

Department of Pathology, Siirt State Hospital,

Siirt, Turkey

\section{Introduction}

Uterine adenofibroma was first described by Ober in 1959 as a form of mixed mesodermal tumor in which the stromal and epithelial components are benign. Cervical adenofibroma is a rare disorder and accounts for $10 \%$ of uterine adenofibromas. The tumor is clinically and histologically benign [1, 2]. However, multiple recurrences [3], local invasion [4] and involvement by adenocarcinoma [5] have been reported. Adenofibromas occur most frequently in peri- or postmenopausal women and symptoms are usually abnormal genital bleeding [6].

We present a patient with an adenofibroma of the uterine cervix.

\section{Case report}

A 55-year-old- woman, gravida 4 para 4 , was admitted to the gynecology clinic at Siirt Women's Health and Children's Hospital in January 2007 with the chief complaint of genital bleeding that she had been experiencing for about 3 months. Her past medical history included hypertension.

Gynecologic examination revealed a firm, pedunculated $2 \times 2 \mathrm{~cm}$ polypoid lesion on the cervix and slightly enlarged uterus. Laboratory data were unremarkable. A diagnostic polypectomy was performed. Microscopically, the tumor consisted of benign dilated cystic endometrial glands and stromal components. Histopathological findings of the cervical biopsy specimen confirmed the diagnosis cervical adenofibroma (Fig. 1). 
Fig. 1 The tumor consisted of an admixture of fibroconnective tissue which forms papillary projections and large irregular glands lined by endocervicaltype epithelium
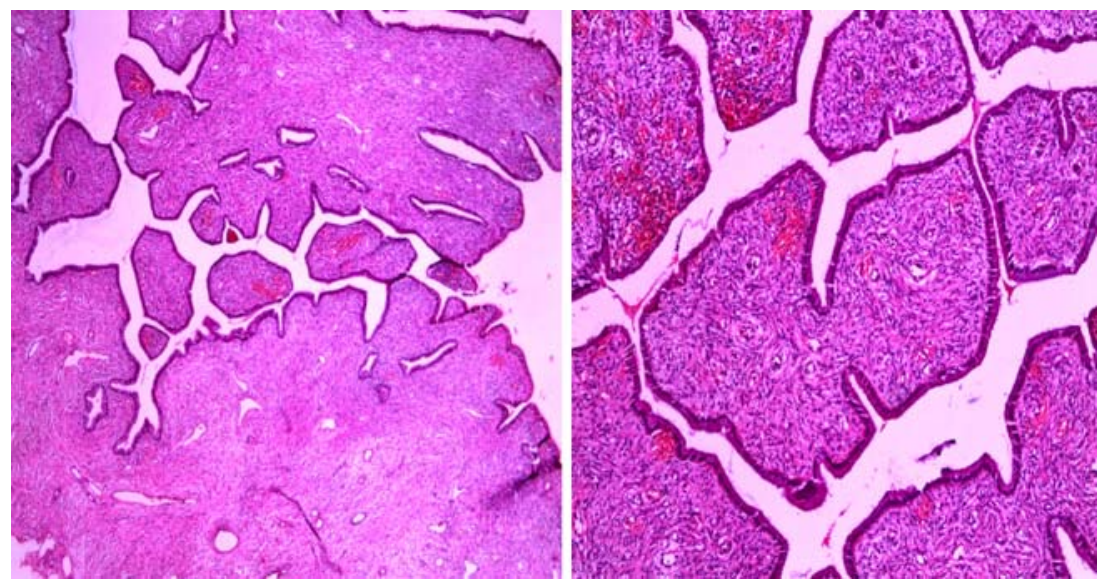

At laparotomy, examination of the pelvis revealed a slightly enlarged uterus. Total hysterectomy with bilateral salpingoophorectomy was performed. Postoperative pathological examination revealed that this lesion did not extend to the endometrium.

\section{Discussion}

Mixed mesodermal tumors contain both epithelial and mesencymal cells, which comprise a rare group of uterine lesions, and the exact clinical and pathological features of the lesions are still being defined. They can be subdivided into benign and malignant lesions. Benign lesions include adenofibroma and adenomyoma. Malignant lesions include adenosarcoma, carcinosarcoma (malignant mixed tumor), and carcinofibroma.

Adenofibroma most commonly arises from the endometrium, but $10 \%$ of the tumors originate in the cervix [7]. They usually present as broad-based polypoid masses that often have villous and spongy cut surfaces with cystic spaces surrounded by firm tissue [8].

Adenofibromas can be seen in patients of any age, but they occur most frequently in peri- or postmenopausal women [6]. The most common presenting symptom is abnormal vaginal bleeding. Some patients have a history of prior removal of polyps or a history of tamoxifen therapy [9].

It is clinically important to distinguish adenofibromas from adenosarcomas. Clement and Scully [7] have recommended the following criteria for the pathologic diagnosis of adenosarcoma rather than adenofibroma when one or more of the following signs are present: a stromal mitotic count of $\geq 2$ per 10 high power fields (HPF), marked stromal cellularity, and more than mild degrees of stromal nuclear atypia. On the other hand, Zaloudek et al. [10] suggested that adenosarcomas should be diagnosed when mitosis is more than 4 cells in $10 \mathrm{HPF}$. The histological differential diagnosis of adenofibroma and adenosarcoma includes endometrial polyps, which are at the benign end of the histologic spectrum, and carcinosarcoma and endometrial stromal sarcoma, at the malignant end.

Hysterectomy is the preferred treatment for an adenofibroma because the neoplasm may recur if it is not completely curetted or excised [3]. Moreover, there is a report that adenofibromas can change to adenosarcomas [3].

Acknowledgements We thank Dr. Mengü Tug at Zekai Tahir Burak Women Health Research and Education Hospital for conclusive discussions.

\section{References}

1. Abell MR (1971) Papillary adenofibroma of the cervix. Am J Obstet Gynecol 110:990-993

2. Velios F, Ng ABP, Reagen JW (1973) Papillary adenofibroma of the uterus. Am J Clin Pathol 60:543-551

3. Seltzer VL, Levine A, Spiegel G, Rosenfeld D, Coffey EL (1990) Adenofibroma of the uterus: multiple recurrences following wide local excision. Gynecol Oncol 37:427-431

4. Clement PB, Scully RE (1990) Mullerian adenofibroma of the uterus with invasion of myometrium and pelvic veins. Int $\mathrm{J}$ Gynecol Pathol 9:363-371

5. Miller Kn, Mcclure SP (1992) Papillary adenofibroma of the uterus. Report of a case involved by adenocarcinoma and review of literature. Am J Clin Pathol 97:806-809

6. Haberal A, Cil AP, Güneș M, Cavüsoglu D (2005) Papillary adenofibroma of the cervix: a case report. Ultrasound Obstet Gynecol 26:186-187

7. Clement PB, Scully RE (1990) Müllerian adenosarcoma of the uterus: a clinicopathologic analysis of 100 cases with a review of the literature. Hum Pathol 21:363-81

8. Lee HK, Kim SH, Cho JY (1998) Uterine adenofibroma and adenosarcoma: CT and MR findings. J Comput Assist Tomogr $22: 314-316$

9. Oshima H, Miyagawa H, Sato Y, Satake M, Shiraki N, Nishikawa H, Arakawa A, Oginı H, Hara M (2002) Adenofibroma of the endometrium after tamoxifen therapy for breast cancer: MR findings. Abdom Imaging 27:592-594

10. Zaloudek CJ, Norris HJ (1981) Adenofibroma and adenosarcoma of the uterus. A clinicopathologic study of 35 cases. Cancer $48: 354-366$ 